\title{
Resident cardiac stem cells on fibrous poly (L-lactide) patch augment cardiac repair via in-patch differentiation and simultaneous migration into infarcted heart tissue
}

\author{
Heiwon Kyung" ${ }^{1 \#}$, Heejung Kim ${ }^{1 \#}$, Hye-Jin Chung${ }^{1}$, Seung Jin Lee ${ }^{*}$, In Kyong Shim ${ }^{2}$, Huining He², Victor C Yang ${ }^{3}$ Jong-Tae Kim ${ }^{4}$, Soon-ho \\ Cheong $^{4}$, Tae-Hyun Yang ${ }^{4}$ and Young-Il Yang ${ }^{4 *}$ \\ ${ }^{1}$ College of Pharmacy, Ewha Womans University, 52, Ewhayeodae-gil, Seodaemun-gu, Seoul 03760 Republic of Korea \\ ${ }^{2}$ Asan Institute for Life Sciences, Asan Medical Center, University of Ulsan College of Medicine, 88, Olympic-ro 43-gil, Songpa-gu, Seoul 05505 Republic of Korea \\ ${ }^{3}$ Tianjin Key Laboratory on Technologies Enabling Development of Clinical Therapeutics and Diagnostics, School of Pharmacy, Tianjin Medical University, \\ Tianjin 300070, China \\ ${ }^{4}$ Paik Institute for Clinical Research, Inje University College of Medicine, 75, Bokji-ro, Busanjin-gu, Busan 47392 Republic of Korea \\ \#These authors contributed equally to this work
}

\begin{abstract}
Stem cell therapy has attracted attention as a promising strategy for treating myocardial infarction; however, low survival and engraftment rates of transplanted cells remain primarily obstructive to their therapeutic outcome. Poly (L-lactide) (PLLA) fibrous patch could direct concentrated implantation of cardiac stem cells (CSCs) onto the infarcted heart. In vivo luminescence imaging revealed that the patch provided a suitable microenvironment for maintaining of the cell viability and population at the site of implantation. In-patch differentiation of CSCs into cardiomyocytes induced construction of multilayered myocardium-like structure without using differentiation-inducing reagent. The result from CM-DiI ${ }^{+}$cell tracking implied transepicardial migration and integration of CSCs via the patch into the infarcted myocardium at the site of implantation. The migrated CSCs were differentiated into cardiomyocytes, vascular endothelial cells and smooth muscle cells resulting in cardiac tissue regeneration and cardiac structural improvement. Myocardial regeneration both in patch and infarcted host myocardium contributed to significant improvement of cardiac performance (CSC-seeded 3-D patch group (EF:51.5 $\pm 2.8 \%$; FS:23.4 $\pm 1.4 \%$ ) in contrast to the patch only group (EF:37.4 \pm $2.8 \%$; FS:16.0 $\pm 0.8 \%)$ ). Epicardial implantation of CSCs via the 3-D PLLA patch may provide a valuable therapeutic modality for myocardial repair.
\end{abstract}

\section{Introduction}

Myocardial infarction (MI) remains one of the leading causes of morbidity and mortality worldwide due to the limited regenerative capacity of the myocardium [1]. The current surgical intervention and pharmacological treatment for MI may not be effective with the exception of heart transplantation [2]. As a novel therapeutic strategy for fulfilling these unmet clinical needs, stem cell therapy has attracted a great deal of interest as a means of replacing damaged myocardial tissue, thereby restoring cardiac function [3]. The therapeutic mechanisms of stem cell therapy include direct reconstitution of the heart cells via differentiation, as well as paracrine effects, which promote endogenous regenerative mechanisms such as the release of regeneration-related cytokines, activation of resident cells and prevention of apoptosis [4]. In stem cell-based cardiac regeneration, the following issues might be considered; 1) in vivo differentiation and host integration, 2) acquisition of the cells, and 3) optimal administration route [5].

Even though numerous clinical and preclinical trials have shown encouraging results with stem cell therapy to ischemic heart, most of them elucidated that cardiac functional improvement after transplantation of the stem cells may be attributed to the paracrine effects of the cells [6] rather than the differentiation into competent cells consisting of myocardium. Several literatures verified the fate of cells after transplantation in terms of their host engraftment and further differentiation into mature cells by using fluorescent cell tracker [7] and their colocalization with mature-cell specific markers $[8,9]$. Nevertheless, some ambiguity still remains on the mechanisms of engraftment of stem cells and their subsequent beneficial effects to the ischemic cardiac zone [10].

To date, various types of stem cells have been used for cardiac regeneration including embryonic stem cells, adult stem cells and induced pluripotent stem cells. Of these, adult stem cells are the most

${ }^{\star}$ Correspondence to: Seung Jin Lee, College of Pharmacy, Ewha Womans University, 52, Ewhayeodae-gil, Seodaemun-gu, Seoul 03760 Republic of Korea, Tel: +82-2-3277-3046; Fax: +82-2-3277-3051; E-mail: sjlee@ewha.ac.kr

Young-Il Yang, Paik Institute for Clinical Research, Inje University College of Medicine, 75, Bokji-ro, Busanjin-gu, Busan 47392 Republic of Korea, Tel: +8251-890-6630; Fax: +82-51-894-6709; E-mail: pathyang@inje.ac.kr

Key words: Cardiac stem cell; Cardiac repair; Transepicardial migration; Poly(L-lactide) fibrous patch

Received: October 01, 2018; Accepted: October 09, 2018; Published: October 12,2018 
Kyung H (2018) Resident cardiac stem cells on fibrous poly (L-lactide) patch augment cardiac repair via in-patch differentiation and simultaneous migration into infarcted heart tissue

common for clinical trials due to their ready availability and wellestablished safety record [11]. Tissue resident cardiac stem cells (CSCs) have emerged as attractive sources for myocardial regeneration due to their strong intrinsic roles in cardiac homeostasis and greater potential to differentiate into cardiac-committed tissue [12] in comparison with other mesenchymal stem cells (e.g., hematopoietic, bone-marrow, or adipose-derived stem cells) [13] showing limited differentiation capacity into cell types pertinent to cardiac regeneration.

However, the rarity of CSCs has been posed as significant challenge in their therapeutic application. Clinical translation of CSCs requires an efficient method for attaining therapeutic quantities of cells ensuring the integrity, function, and safety of the cells destined for use in patients. Myocardial specimen, the source of CSCs, should be attained by surgical resection of heart. A previous study reported that the population of cells with stem cell-like activity comprise $1 \sim 2 \%$ of the cells in the heart [14]. In this regard, efficient methods for isolation of CSCs from the limited myocardial biopsy samples and their ex vivo expansion are crucially important for their clinical translation, which are required to obtain therapeutically effective amount of the cells with optimal quality in companion with clinical and commercial consideration. Current stem cell isolation methods can be classified into two major techniques; enzymatic methods and explant culture method [15]. For specific separation of CSCs from heterogeneous cell populations in myocardial biopsies, immunoselecting procedures were required including fluorescence or magnetic activated cell sorting (FACS or MACS) in the enzymatic methods [16]. However, those might result in insufficient depletion of undesired cells, loss of important cell surface markers and membrane integrity of cells due to lytic stress, which leads to dysfunction of the sorted cells and lack of reproducibility. In contrast, explant culture methods isolate the cells spontaneously shed from the myocardial specimen then select upon the ability of forming clusters called cardiospheres [17,18]. Explant culture methods possess several advantages over enzymatic procedures, which allows for greater number of intact CSCs by cost, processing time and labor reduction [15]. However, physical contact between explanted tissue and the culture dish is insecure in conventional explant methods, which is essential for cell migration or outgrowth. In our previous research, fibrin-supported organ culture method was invented to provide explanted myocardium sufficient physical contact and mechanical support by mimicking endogenous microenvironment in heart, possibly leading to enhancement of cell renewal and outgrowth [19].

The choice of the administration route in stem cell therapy is extremely important for successful myocardial repair because it affects the survival, retention, integration and functionality of the administered cells and subsequently influences therapeutic outcome [20]. Intracoronary or intravenous cell infusion are the most commonly used routes for administration of stem cells to the heart due to their simplicity and minimal invasiveness $[21,22]$. However, most of the cells administered through these routes are lost rather than engrafted onto infarcted myocardium, resulting in inadequate therapeutic efficacy. Injection of concentrated cell suspension might risk microvascular obstruction or embolism [21]. Intramyocardial injection was chosen for enhancing retention rate of cells in site-specific manner [23] while remains concerned due to its low cell survival and additional risks including potential arrhythmia and myocardial perforation and leakage of injected cells at the site of injection [21]. Epicardial cell delivery has emerged as a promising strategy to enhance cell survival and site-specific engraftment on the infarcted zone of the heart [24,25]. Diverse scaffolds have been attempted for epicardial implantation of cells including acellular/cellular patches made of natural or synthetic polymers [9,26-28]. Most of epicardially applied devices are a patch-type so that they could be entirely attached onto the injured myocardium. However, conventional devices has 2-dimensional (2-D) membraneous structure which hamper cell delivery with high quantity and viability in addition to lack of vascularization. Cell sheet technology, which have been adopted as a novel scaffold-free 3-dimensional cell transplantation strategy to graft large amount of cells in forms of celldense constructs, also have similar challenges subsequently hindering the functional survival of the grafts due to their resistance to new blood supplies and thus susceptible to necrosis [29].

In this study, a biodegradable 3-dimensional (3-D) patch-type fibrous scaffold was designed for directed delivery of CSCs onto damaged myocardium and investigate the therapeutic mechanism of CSCs with the scaffold in treating damaged myocardium. Our hypotheses include 1) the 3-D patch can provide microenvironment to differentiate CSCs into cardiomyocyte, 2) epicardially delivered CSCs via the $3-\mathrm{D}$ patch could migrate into the damaged myocardium and further differentiated into matured myocardial cells, which can replace the scarred tissue. This study will describe administration of CSCs via a biodegradable 3-D patch-type scaffold could achieve a synergistic effect on the structural and functional recovery of defective myocardium in a rat acute MI model.

\section{Materials and Methods}

\section{Cell isolation and culture}

CSCs were isolated by fibrin-supported organ culture based on the method previously reported in our laboratories [19]. Isolated cells were sub-cultured on tissue culture plates in growth medium until the third passage. All animal experiments were approved by the Institutional Animal Care and Use Committee at Inje University School of Medicine.

\section{Fabrication of PLLA 3-D patch and characterization}

Poly-(L-lactide) were kindly provided by Purac Biochem (Purac Biochem BV, Gorinchem, Netherlands) and PLLA patches were prepared as described [30] with minor modifications. Briefly, PLLA (intrinsic viscosity $=0.63 \mathrm{dl} / \mathrm{g}, \mathrm{Mw}=2.5 \times 105 \mathrm{~g} / \mathrm{mole}$ ) solutions at a concentration of $20 \%(\mathrm{w} / \mathrm{v})$ were prepared in methylene chloride (MC) and acetone (AC) (Sigma-aldrich, St. Louis, MS, USA) solution (90:10 $\mathrm{v} / \mathrm{v})$. The polymer solution was placed in a $10 \mathrm{ml}$ syringe capped with a 23-gauge blunt end needle (Nano NC, Seoul, Korea). A high-voltage supply of $10 \mathrm{kV}$ was used, and the solution flow rate was fixed at $0.1 \mathrm{ml} /$ min. The distance between the needle tip and the collector was $15 \mathrm{~cm}$. The fibers were collected on a rotating mandrel at a speed of $2000 \mathrm{rpm}$, and formed nonwoven 3-D fibrous patches with a thickness of $1 \mathrm{~mm}$. The electrospun patches were freeze-dried for 3 days to evaporate the solvent. Prior to use, the electrospun scaffolds were cut into rectangles $(5 \times 10 \mathrm{~mm})$ for in vitro and in vivo studies. Expanded patches were prepared by mechanical expansion so that their volume increased by approximately 7 -folds. To fabricate 2 - D patches as a control, $3 \%$ PLLA was dissolved in a mixture of MC and HFIP $(90: 10 \mathrm{v} / \mathrm{v})$, and then electrospun at $16 \mathrm{kV}$ at a flow rate of $0.06 \mathrm{ml} / \mathrm{min}$. The morphological features of the 3-D and CSC-seeded patches were observed by SEM (JSM 5200, JEOL, Tokyo, Japan). Average fiber diameter and pore size were calculated using a SEM measurement program. The specimens were sputter-coated with gold (POLARON SC7620, ThermoVG Microtech, England) prior to the SEM imaging study. The degradation properties of the 3-D patch were examined by measuring the weight loss for 42 days. The patch was incubated with constant agitation at 30 rpm in $1 \mathrm{~mL}$ of $\mathrm{PBS}, \mathrm{pH} 7.4$, at $37^{\circ} \mathrm{C}$. The medium was exchanged at 
Kyung H (2018) Resident cardiac stem cells on fibrous poly (L-lactide) patch augment cardiac repair via in-patch differentiation and simultaneous migration into infarcted heart tissue

defined time intervals. The sample taken from the media was examined to calculate the weight loss after vacuum drying. The morphology of the degraded matrix was evaluated over time to verify patch degradation using a scanning electron microscope (JEOL, Tokyo, Japan).

\section{Cell culture in 3-D PLLA patches}

The CSCs were sub-cultured at the fifth passage, and $2 \times 105$ CSCs were suspended in $50 \mu$ of culture medium. The CSC suspension was seeded into the 3-D patches and incubated for $2 \mathrm{~h}$ at $37^{\circ} \mathrm{C}$ in $5 \% \mathrm{CO}_{2}$. After the CSCs on the patch were stabilized, growth medium was added, and the cells were cultured under the same conditions for 2 weeks. Complete medium consisted of DMEM/Ham's F12 (1:1), 10\% fetal bovine serum (Thermo scientific, Waltham, MA, USA), $10 \mathrm{ng} / \mathrm{ml}$ EGF, $2 \mathrm{ng} / \mathrm{ml} \mathrm{bFGF}$, and $10 \mathrm{~g} / \mathrm{ml}$ gentamicin (Sigma-Aldrich, St. Louis, MS, USA).

For SEM analysis, the CSC-seeded 3-D patches were cultured for 1 day, and then fixed with a $2.5 \%$ glutaraldehyde solution at $4{ }^{\circ} \mathrm{C}$ and repeatedly rinsed with PBS (Thermo scientific, Waltham, MA, USA) at room temperature. The samples were placed in $\mathrm{OsO}_{4}$ solution (Sigma-Aldrich, St. Louis, MS, USA) and rinsed with PBS. Following washing, all of the samples were dehydrated using a series of chilled ethanol solutions $(70 \%, 80 \%, 90 \%, 95 \%$, and $100 \%)$, and then placed in a 1,1,1,3,3,3-hexamethyl disilazane solution (Sigma-Aldrich, St. Louis, MS, USA) for $1 \mathrm{~h}$. The samples were dried at room temperature before morphological analysis by SEM.

Cell proliferation assays were performed after 1, 3, 7, and 14 days of culture using the Cell Counting Kit-8 (CCK-8) (Dojindo, Kumamoto, Japan). CSCs $\left(1 \times 10^{5}\right)$ were seeded into the patch and incubated for 2 $\mathrm{h}$ to allow cell attachment, and the CSC-seeded patches were cultured in growth medium for 2 weeks. Cell numbers in the CSC-Patch constructs were determined by measuring absorbance $(450 \mathrm{~nm})$ of reduced WST-8 (2-(2- methoxy-nitrophenyl) 3-(4-nitrophenyl)-5(2,4-disulfophenyl)-2H-tetrasolium, monosodium salt). For this assay, CSC-seeded patches were washed with PBS before the addition of serum-free medium, including the CCK- 8 solution. Samples were incubated for $3 \mathrm{~h}$ at $37^{\circ} \mathrm{C}, 5 \% \mathrm{CO}_{2}$. The incubated solution $(200 \mu \mathrm{l})$ was transferred to a 96-well culture plate, and optical densities were measured using a microplate reader. To calculate cell numbers, standard curves were plotted using serial dilutions of the same cell used in this study. To determine the permissive role in cardiomyogenic differentiation of CSCs in the patches, $1 \times 10^{6}$ cells were seeded on a 1 $\mathrm{cm}^{2}$ PLLA patch, supplemented with differentiation medium $(50 \mu \mathrm{M}$ ascorbic acid, 0.1\% DMSO, and 1\% FBS suspended in DMEM), and cultured for 7 days. The degree of cardiomyogenic differentiation was assessed by monitoring expression of cardiomyocyte (CMC) - specific proteins by immunofluorescence staining. The cell-seeded patches were fixed in paraformaldehyde solution, and the fixed samples were embedded in paraffin. CMC markers ( $\alpha$-SA, Mhc, and TnI) were stained by isotype-matched Alexa Fluor 488-conjugated secondary antibodies, followed by confocal microscopy.

\section{MI model and patch transplantation}

All of the 3-D patches were repeatedly rinsed with ethanol and PBS. CSCs $\left(2.5 \times 10^{6}\right)$ were seeded on the patches and incubated for 1 day at $37^{\circ} \mathrm{C}$ under $5 \% \mathrm{CO}_{2}$. Patches without CSCs were used as controls. Acute MI was induced in adult male Sprague Dawley (SD) rats (10-weeks old) as described previously [31]. The rats were anesthetized, and the proximal left anterior descending coronary artery was ligated by sutures. After induction of MI, the patches and CSC-seeded patches were implanted over the infarcted area of myocardium using 8-0 Prolene sutures.

To determine the cell retention rate, survival of the implanted CSCs in rat heart was evaluated by noninvasive bioluminescence imaging (BLI). CSCs $\left(2.5 \times 10^{6}\right)$ were transduced with an enhanced firefly luciferase gene (effLuc) using a retroviral vector, and then seeded onto the patches. The CSC-seeded patches were cultured for 1 day to allow cell attachment, and then the effLuc-CSC patches were intramyocardially injected or epicardially implanted over infarcted zones. One day after CSCs transplantation, d-luciferin (R\&D Systems, Minneapolis, MN, USA) was injected, and bioluminescence images were acquired using an IVIS-100 imaging system (Caliper Life Science, Waltham, MA, USA). The bioluminescence intensity was determined and expressed as photons $/ \mathrm{cm}^{2}$ per second.

\section{Histology and immunostaining}

Histomorphometric analysis was performed to determine the cardioprotective effects of CSC-seeded patches. Rats implanted with 3-D patches containing CSCs and sham-operated patches were used as controls. The rats were sacrificed 2 and 4 weeks after implantation, and hearts were fixed with $4 \%$ paraformaldehyde and embedded in paraffin. The ventricular geometry ( 2 weeks) was examined from microphotographs of sectioned hearts acquired at the midpoint between artery ligation and apex. Paraffin sections were stained with hematoxylin-eosin (H\&E) and Masson's trichrome (MT) (4 weeks) to determine fibrotic area, wall thickness, and myocardial regeneration.

For in vivo cell tracing, CM-DiI (Invitrogen, Carlsbad, CA, USA)labeled CSCs were epicardially implanted using 3-D patches on the area of infarcted myocardium. After 2 weeks of recovery, the hearts were fixed with $4 \%$ formalin, and paraffin sections were prepared. The markers of CMCs (Sarcomeric actinin (SA), troponin I (cTnI), and myosin heavy chain (Mhc)), endothelial cells (EC) (IB4), and vascular smooth muscle cells (SMCs) (SMA) were stained by incubation with isotype-matched Alexa Fluor 488-conjugated secondary antibodies. Nuclei were stained with diamidinophenylindole (DAPI, blue). Antibodies were visualized using the EnVision" system (DAKO, Seoul, Korea) and 3,3'-diaminobenzidine (Sigma- Aldrich, St. Louis, MS, USA), followed by confocal microscopy. To determine the transepicardial migration and homing ability of CSCs, $2.5 \times 10^{6}$ CSCs at P3 labeled with CM-DiI were onto the patches. After induction of MI, the CM-DiI labeled CSC-seeded patches were implanted over the infarcted area of myocardium. After $14 \mathrm{~d}$ of infarction, the hearts were recovered, sliced along the short axis, made into paraffin blocks, and counterstained with DAPI. All sections were examined by a confocal microscopy. The cell density of each section was analyzed by using Image J (NIH, Bethesda, MD, USA) and expressed as cell number $/ \mathrm{mm}^{2}$ for histomorphometric assessment.

To monitor angiogenesis and vascular ingrowth into PLLA patches and myocardium, immunofluorescence staining against SMA was performed. The sectioned samples were incubated with primary antibody against SMA, followed by horseradish peroxidaseconjugated secondary antibody, and signals were visualized with 3,3-diaminobenzidine. $\mathrm{SMA}^{+}$microvessel density in infarcted areas of the patch and CSC-seeded patch groups was determined using ImageJ (NIH, Bethesda, MD, USA). The numbers of SMA+ microvessels were assessed in five randomly selected areas per sample.

\section{Echocardiography data analysis}

To analyze cardiac functions, echocardiographic evaluation was performed using the VIVID 7-dimension system (GE Healthcare, 
Kyung H (2018) Resident cardiac stem cells on fibrous poly (L-lactide) patch augment cardiac repair via in-patch differentiation and simultaneous migration into infarcted heart tissue

Seoul, Korea). The data were assessed using a $13 \mathrm{MHz}$ linear transducer with high frame-rate imaging $(102 \mathrm{~Hz})$. Parasternal long-axis and short-axis views of the left ventricle (LV) were obtained, and M-mode tracing images and cine loops of two-dimensional echocardiography were recorded. Ejection fraction (EF) and fractional shortening (FS) to assess LV function were calculated using Echo Pac (GE Healthcare Systems).

\section{Statistical analysis}

Results obtained from five to nine independent experiments were analyzed by Student's $\mathrm{T}$ test. Values represent means \pm standard deviation. $\mathrm{P}<0.05$ was considered statistically significant.

\section{Results}

\section{Characterization of 3-D PLLA patch}

Figure $1 \mathrm{~A}$ illustrates the significant expandability of the 3-D patch. Fiber orientation can be easily enforced by bidirectional tugging as shown figure 1A. The 3-D patch used in this study was composed of separative polymeric fibers, and can be tailored to have a fluffy structure with sufficient spatial volume for infiltration of the seeded cells (red arrows).

Figure 1B showed degradation profile of the 3-D patch. For 42 days, approximately $40 \%$ of the total weight decreased (Figure 1B). As the degradation continued, pores developed over time, increasing void volume in the scaffold in SEM microscopy.

The SEM images show the alignment of microfibers of the 3-D patch and the attached CSCs onto the patch (Figure 1C). This structural feature of the patch was achieved by controlling the rotating speed rate of the collector to mimic the topology of native myocardium, which consists of layers of aligned myocytes, thereby inducing directed and aligned cellular adhesion onto the 3-D patch. Seeded CSCs aligned along the fibers and infiltrated into the 3-D patch through the pores (red arrows).

\section{In vitro $\mathrm{CSC}$ proliferation and differentiation within the $3-\mathrm{D}$ patch}

The seeded CSCs remained viable on the 3-D patch with robust proliferation in the growth media up to 2 weeks (Figure 2A), indicative of the compatibility of the 3-D patch as a delivery carrier of CSCs. $98 \%$ of cells were detected $2 \mathrm{~h}$ after the procedure, implying that most of the seeded cells resided in the patch. More than $2 \times 10^{5}$ cells per $\mathrm{mm}^{2}$ could be seeded onto the $3-\mathrm{D}$ patch without influencing their survival rate.

Figure 2B shows newly formed myocardium-like construct from CSC-seeded 3-D patches in vitro after cultured in differentiation medium for 2 weeks. The construct consists of stratified immature CMCs expressing markers including TnI, Mhc, and a-SA without showing necrotic region. The presence of CMCs indicates that 3-D patch successfully acted as a permissive substratum for spontaneous differentiation of CSCs into CMCs.

\section{Enhanced retention of CSCs delivered via 3-D patch into infarcted heart}

Intense bioluminescence signals were observed in the CSC seeded patch-implanted hearts, indicating that a large number of implanted CSCs incorporated in 3-D patches persisted and survived in infarcted hearts in vivo (Figure 3). However, relatively weak luciferase activity was detected in the CSC-intramyocardial injection group (CSC-IM)
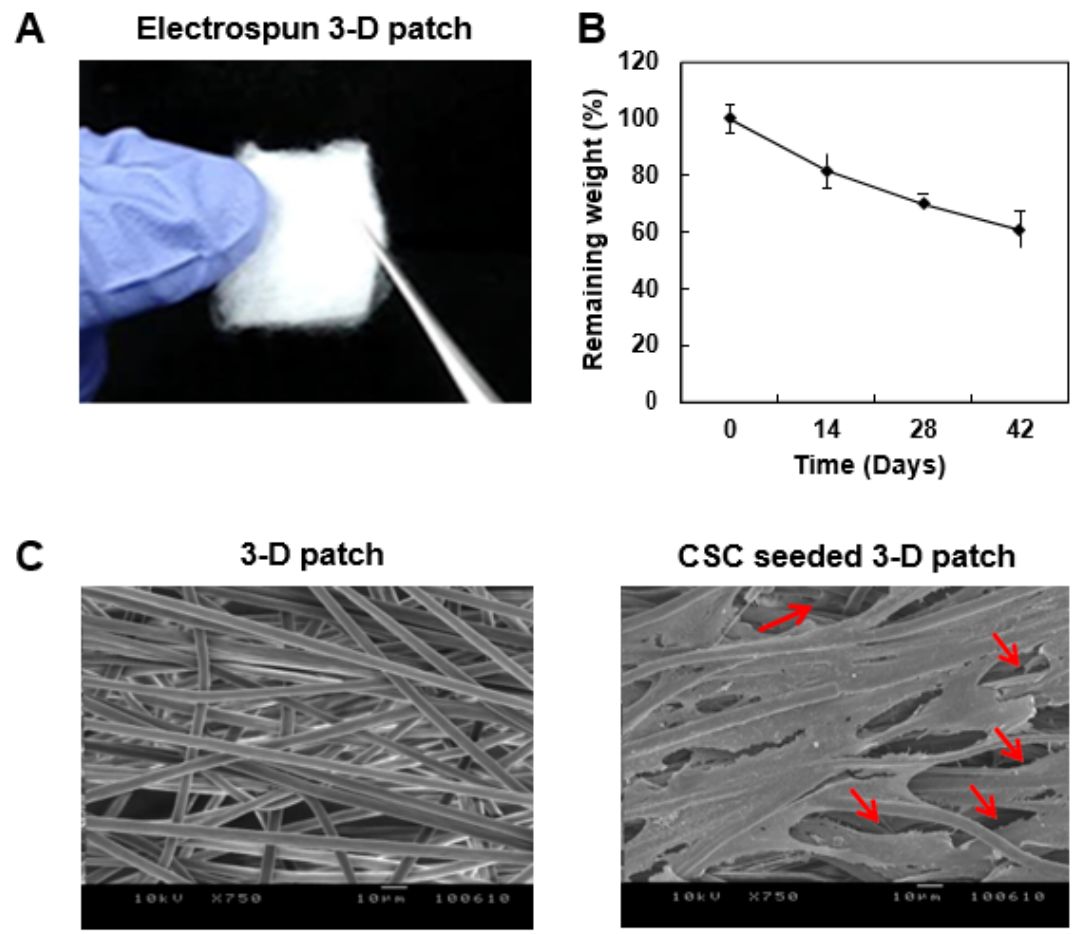

Figure 1. Morphological features of the 3-D fibrous patch for cardiac stem cells engraftment. (A) Optical image of the 3-D fibrous patch. The patch is composed of unbound PLLA fibers made by electrospinning process, which is expanded for suitable appliance onto the injured myocardium. (B) In vitro degradation profile of the 3-D patch. Changes in weight were measured after $0,14,28,42$ days of immersion in PBS (pH 7.4) with mild agitation (30 rpm) at $37{ }^{\circ} \mathrm{C}$. The assay was quadruplicated. ( $\left.\mathrm{n}=4\right)$ (C) Representative SEM image of PLLA 3-D patch and cardiac stem cell (CSC)-seeded patch a day after culture in growth media. The cells were well-infiltrated throughout the fibrous structure of the 3-D patch (red arrows) in addition to directionality of the bound cells in aligned fibrous structure of the mat. Scale bar $=10 \mu \mathrm{m}$ 
Kyung H (2018) Resident cardiac stem cells on fibrous poly (L-lactide) patch augment cardiac repair via in-patch differentiation and simultaneous migration into infarcted heart tissue

A

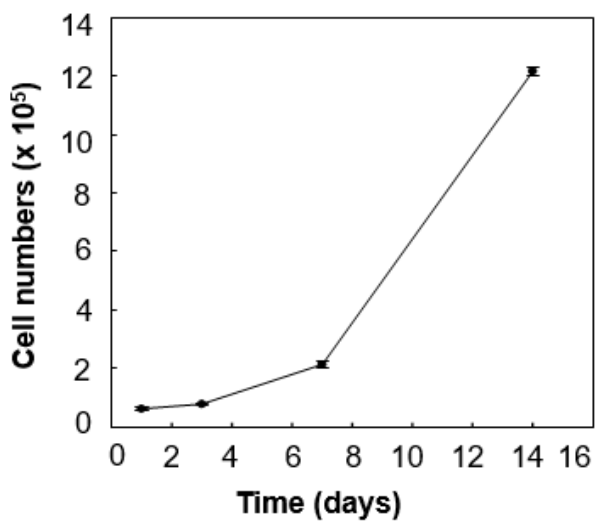

B

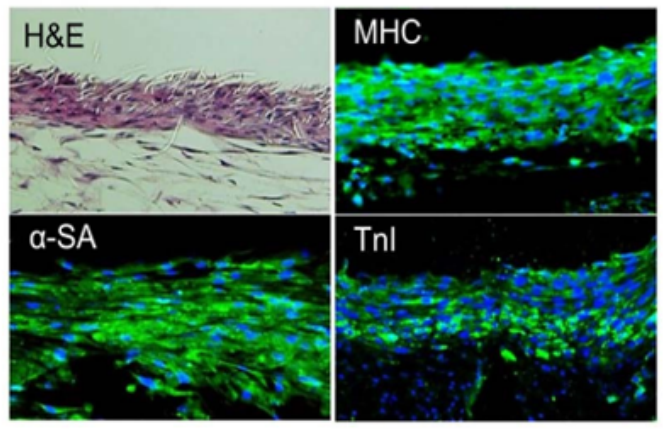

Figure 2. Permissive role of 3-D mat in cell attachment, proliferation, and cardiomyogenic differentiation of CSCs. Proliferation of CSCs in the 3-D patch for 2 weeks. Cell numbers in each timepoint were calculated by measuring colorimetric change at $450 \mathrm{~nm}$ absorbance according to Cell Counting Kit-8 (CCK-8) assay method. Representative microphotographs of CSC-seeded 3-D patch. The CSCs in the patch were elongated and adhered each other forming stratified, myocardium-like structure after cultivation in differentiation media for 7 days. Green fluorescence represented expression of cardiomyocyte (CMC)-specific proteins ( $\alpha$-sarcomeric actinin; $\alpha$-SA, myosin heavy chain; Mhc, and troponin T; TnI), indicative of CMC differentiation of the CSCs in the patch
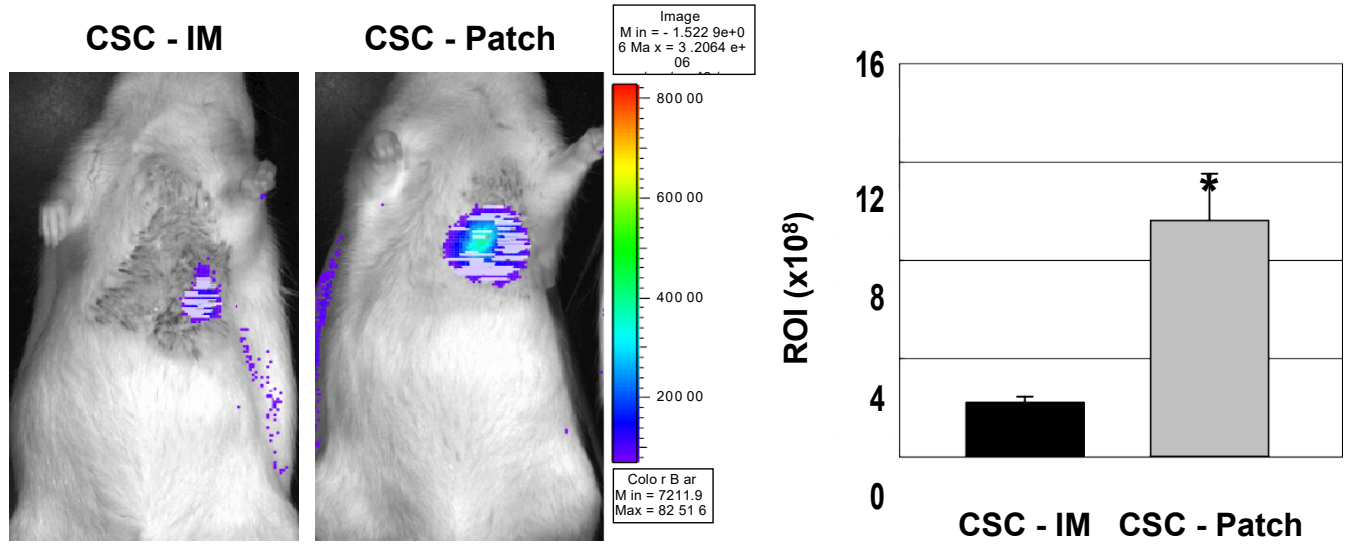

Figure 3. Retention rate of CSCs according to delivery routes in rat acute MI model. Enhanced firefly luciferase (effLuc) gene-transduced CSCs $\left(2.5 \times 10^{6}\right)$ were transplanted to Sprague Dawley rat by direct intramyocardial injection (CSC-IM) or 3-D patch-mediated epicardial implantation (CSC-Patch). Luminescence signal of the cells were clearly visualized in the grafted region. Quantitative analysis of region of interest (ROI) value showed a greater number of CSCs onto the site of interest in CSC - Patch group. $\left(n=6,{ }^{*}, \mathrm{p}<0.005\right)$

comparing with CSC-seeded patch (CSC-Patch) group. Region of interest (ROI) analysis revealed the significant difference in CSCs delivery efficiency of the 3 -D patch, approximately 4 -fold higher in vivo bioluminescence signal in the CSC-effLuc patch group relative to the CSC injection group. These results demonstrated that the 3-D patch significantly improved the survival rate and engraftment efficiency of CSCs at the site of implantation.

\section{Engraftment of CSCs delivered via 3-D patch into infarcted heart}

Figure 4 shows topological distribution of $\mathrm{CM}^{-\mathrm{DiI}^{+}}$(red) CSCs in heart after implantation of CSC-seeded patch. CM-DiI ${ }^{+}$cells were not detected in the spared myocardium at the base and occasionally observed in the proximal area (Arbitrary Units (AU) : $7.76 \pm 1.36$ ). In contrast, the cells were dominantly observed at the implanted site (distal area of heart and apex) showing significantly higher fluorescent intensity (Arbitrary Units (AU) : $43.88 \pm 5.88$ and $53.96 \pm 5.23$, respectively). In addition, labeled CSCs were observed both in the patch and the inner part of myocardium (Figure 5). These result presented the 3-D patch enable concentrated and localized delivery of CSCs and epicardially implanted CSCs migrated into the injured myocardium in a convergent manner from the site of implantation.

\section{Cardiogenic differentiation of CSCs delivered via 3-D patch into infarcted heart}

In immunohistochemical analysis, approximately $15 \%$ of $\mathrm{CM}$ $\mathrm{DiI}^{+}$cells co-expressed CMC markers ( $\alpha$-SA, TNI, and Mhc) with a fine striation. Less than $1 \%$ of $\mathrm{CM}-\mathrm{DiI}^{+}$cells differentiated into ECs and SMCs of microvessels, which co-expressed IB4 and smooth muscle actin (SMA), respectively (Figure 6). These results suggested that engrafted CSCs mainly differentiated into CMCs, whereas few CSCs differentiated into endothelial and vascular muscle cells in vivo.

\section{Assessment of myocardial regeneration in vivo after CSC- Patch implantation}

As shown in Figure 7A, The infarct size was significantly lower in the CSC-Patch group than in the patch- only group in addition to reduced post-MI cardiac remodeling such as dilatation and thinning of the ventricle. Moreover, thicker myocardial tissue (black arrows) was observed in the areas adjacent to the CSC-Patch rather than fibrotic tissue in CSC-Patch group. Less inflammatory cells (white arrows) were observed in the implanted patch of CSC-Patch group than the Patch only group. To examine the viability of CSCs and their fate in the 
Kyung H (2018) Resident cardiac stem cells on fibrous poly (L-lactide) patch augment cardiac repair via in-patch differentiation and simultaneous migration into infarcted heart tissue
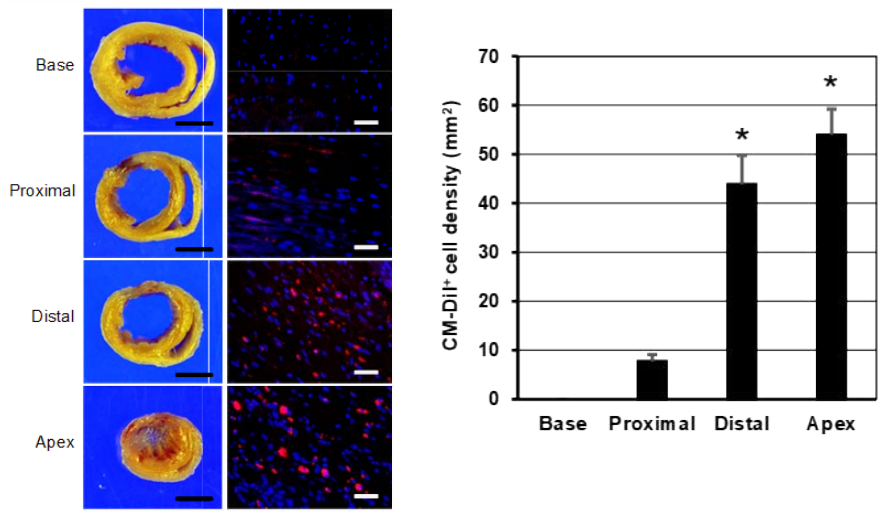

Figure 4. The topographic distribution of the CM-DiI ${ }^{+}$cells in the different parts of heart and the quantitative analysis. Epicardially implanted CSCs were dominantly migrated into the injured myocardium (distal and apex). CM-DiI ${ }^{+}$CSCs were not detected in the spared myocardium at the base and occasionally observed in the proximal area. (Scale bar=3 mm (left) and $200 \mu \mathrm{m}$ (right). *, p $<0.01$ compared with proximal or base)

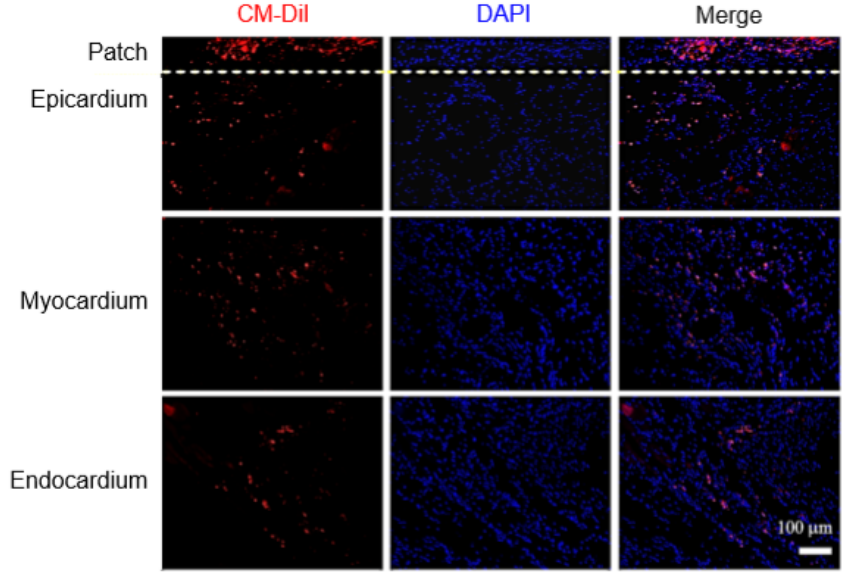

Figure 5. Homing ability and engraftment of epicardially implanted CSCs into the infarcted myocardium. Representative microphotographs of heart sections. CM-Dil labeled CSCs were observed at epicardium 2 week after implantation. Implanted CSCs via the 3-D patch were migrated into the inner part of myocardium (endocardium) from the adjacent area of implantation. (Scale bar $=100 \mu \mathrm{m})$

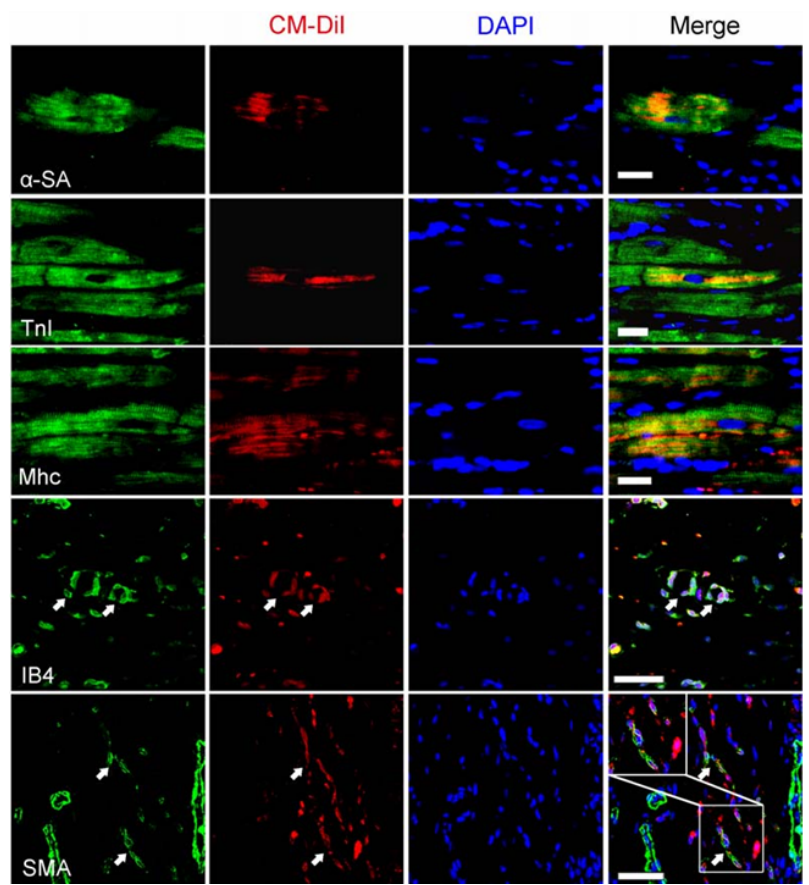

Figure 6. In vivo differentiation of implanted CSCs via the 3-D patch. Representative microphotographs of immunohistochemically stained heart sections. The engrafted cells were differentiated into the cells composing of the native myocardium including cardiomyocyte ( $\alpha-\mathrm{SA}, \mathrm{TnI})$, and Mhc ${ }^{+}$cells), endothelial (IB4 ${ }^{+}$cells), and vascular smooth muscle cell (SMA ${ }^{+}$cells $)$ in the myocardiac tissue. Nuclei were counterstained with diamidinophenylindole (DAPI, blue). White arrows and box marked the merge fluorescent $\left(\mathrm{CM}^{-\mathrm{DiI}}{ }^{+}\right.$and IB4 ${ }^{+}$or SMA ${ }^{+}$) parts indicative of differentiated cells(endothelial cells or smooth muscle cells, respectively) from the transplanted CSCs. ( $\alpha$-SA, alpha sarcomeric actinin, TnI, cardiac troponin I; Mhc, myosin heavy chain; IB4, isolectin B4. SMA, smooth muscle actin; Scale bars $=25 \mu \mathrm{m}$.) 
Kyung H (2018) Resident cardiac stem cells on fibrous poly (L-lactide) patch augment cardiac repair via in-patch differentiation and simultaneous migration into infarcted heart tissue

patch, the CSC-seeded 3-D patch were stained with CMC markers $(\alpha-$ SA and TnI) and DAPI 2 week after the implantation. DAPI staining displayed well-distribution of the CSCs over the 3-D patch. Distinctive green fluorescence were shown in the 3-D patch, which signify CSCs were spontaneously differentiated into mature $\mathrm{CMC}$ remaining viable (Figure 7A, middle, right). To confirm the effect of the 3-D patch and CSC engraftment on neovascularization, $\mathrm{SMA}^{+}$microvessels were counted. In CSC-Patch group, vascularization progressed in the 3-D patch (Figure 7A, bottom, right). As shown in Figure 7B, both Patch only group and CSC-Patch group shows microvessel structures in epicardium. However, the microvessels were more abundant in the CSC-Patch group (1.6-fold) with clear lumen structures than in the Patch-only group.

\section{Assessment of structural and functional improvement of infarcted heart after CSC-Patch implantation}

To evaluate cardiac restoration by epicardial delivery of CSCs via the 3-D patch, histological analyses were performed between the CSCseeded patch (CSC-Patch), patch-only, and sham operation groups. The CSC-Patch group exhibited well-preserved wall thickness and reduced scar area in comparison with the patch-only group. The degree of fibrosis was dramatically rescued in the CSC-Patch group (15.9 \pm $3.8 \%)$ compared with in the patch-only group (42.6 $\pm 9.3 \%)$. The LV wall thickness in the CSC-Patch group $(0.69 \pm 0.2 \mathrm{~mm})$ was 2.6 -fold greater than in the patch-only group $(0.26 \pm 0.0 \mathrm{~mm})$ (Figure $8 \mathrm{~A})$. No significant difference in fibrotic area or LV wall thickness between the sham operation and patch-only groups.
A

\section{A}

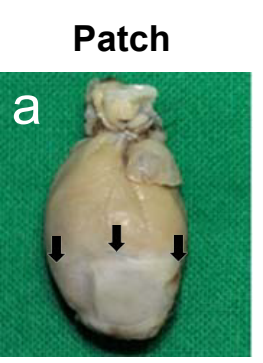

CSC - Patch
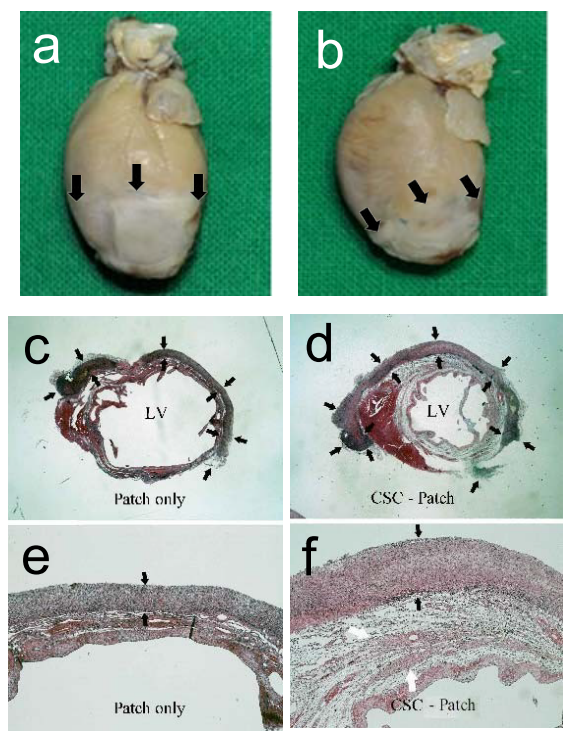

B
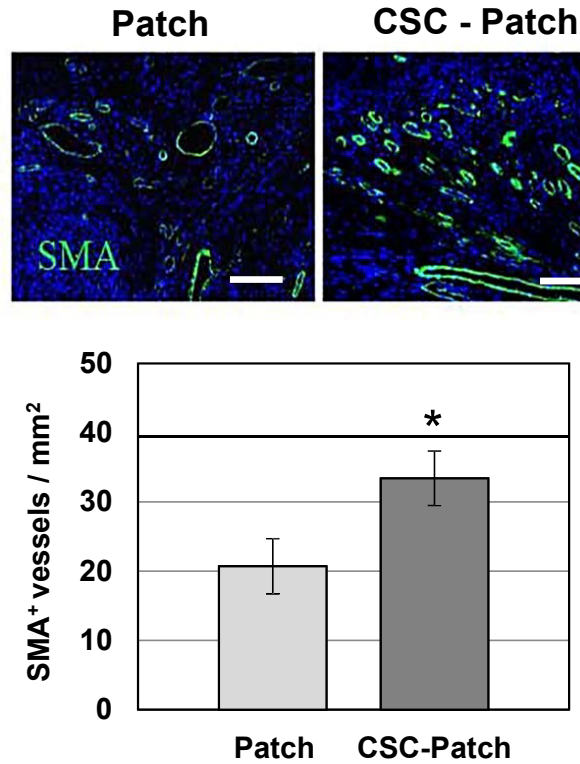

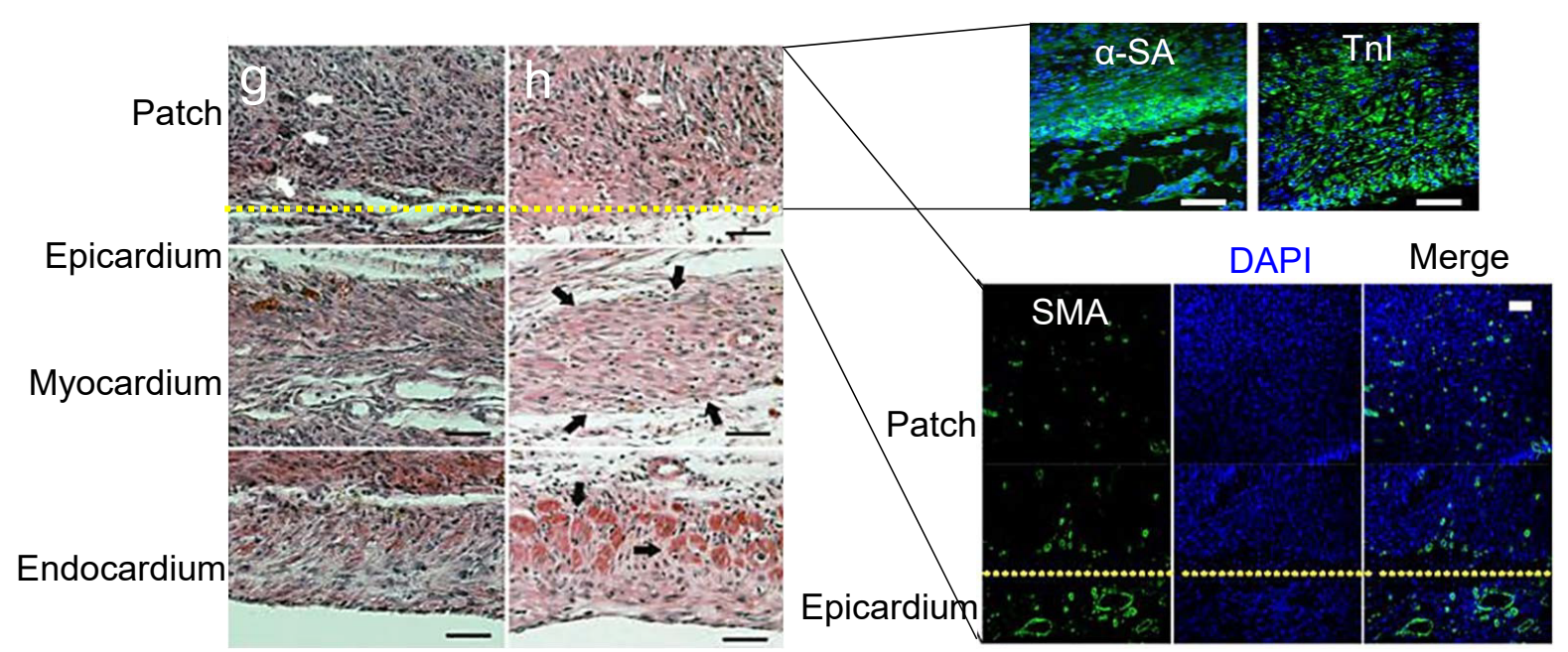

Figure 7. In vivo cardioregenerative effect of CSC transplantation via the 3-D mat. CSCs $\left(2.5 \times 10^{6}\right)$ were seeded onto 3 -D patch then implanted around the infarcted region (a and b, black arrows) of rat myocardial infarction(MI) model prepared by left coronary artery ligation (LAD). Patch-implanted group (Patch) was prepared as a control. (A) Representative microphotographs of heart sections. The paraffinized sections were stained with hematoxylin-eosin (H\&E) and immunochemical reagents 2 weeks after the implantation. Implanted patches were well-integrated to infarcted heart in both patch only group and CSC-Patch group (c and d, black arrows). CSC-Patch group shows thicker neotissue formation in PLLA patch (f, black arrow) and in heart tissue (f, white arrows and h, black arrows) in addition to less multinucleated immune cells (h, white arrows) in the patch. Remarkable green fluorescence describes the existence of mature cardiomyocyte markers ( $\alpha$-sarcomeric actinin; $\alpha$-SA and troponin T; TnI) and microvascular arrangement (Smooth muscle actinin; SMA and lumen structure) in the patch of CSC-Patch group. (Scale bars $=100 \mu \mathrm{m})(\mathrm{B})$ Representative microphotographs of immunofluorescence stained heart sections. Smooth muscle actinin-positive (SMA ${ }^{+}$) microvessel density in the infarcted myocardium was measured 4 weeks after implantation. The vascularity of the infarcted myocardium was significantly increased in CSC-Patch group. ((Scale bars $=100 \mu \mathrm{m} *, \mathrm{p}<0.05$ compared to Patch group) 
A
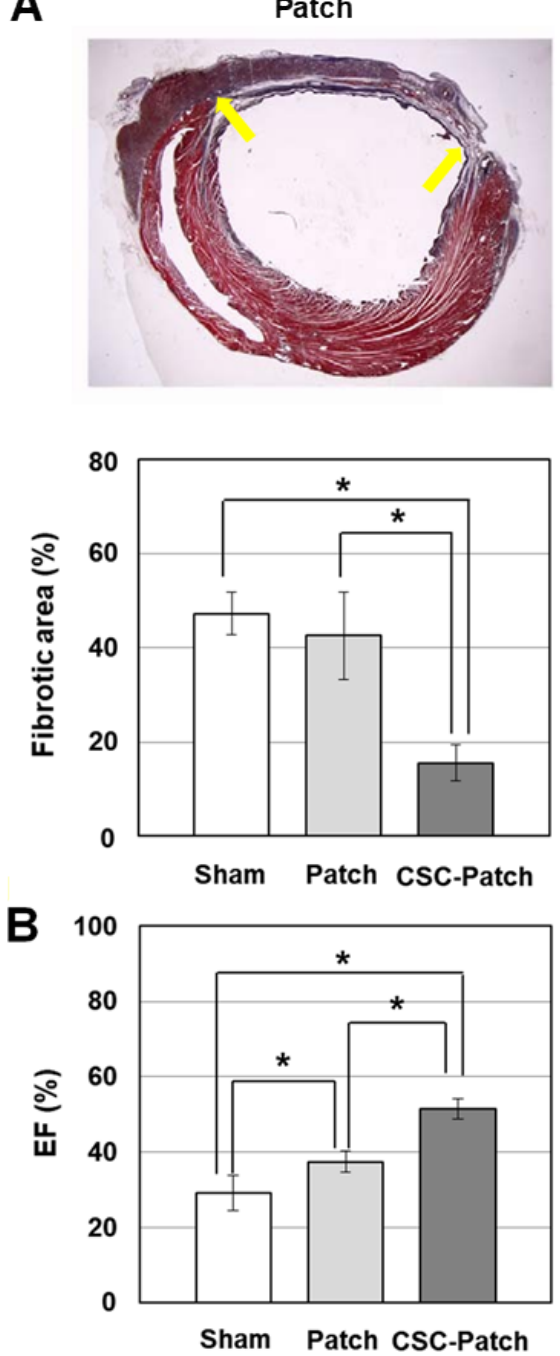

CSC - Patch
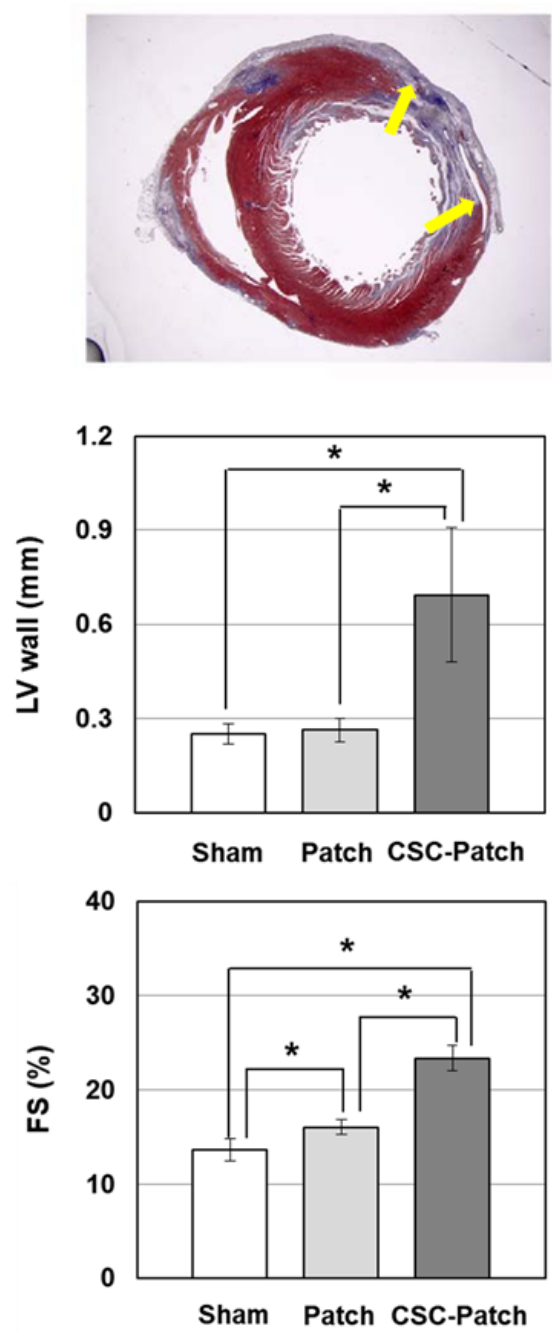

Figure 8. In vivo structural and functional improvement in infarcted heart after implantation of CSCs via the 3-D mat. Fibrotic area, Left ventrical (LV) wall thickness, ejection fraction (EF), and fractional shortening (FS) were compared between the sham operation group, patch-implanted group (Patch), and CSC-seeded patch implanted group (CSC-Patch). (A) Representative microphotographs of heart sections. Wall thickness and fibrous area of the left ventricle (LV) assessed by histomorphometric method (Masson's trichrome staining) after 4 weeks of myocardial infarction. CSC-Patch group shows significantly reduced fibrotic area and increased wall thickness of LV. Yellow arrows indicate fibrotic areas. (B) Global cardiac function assessed by echocardiography after 4 weeks of myocardial infarction. Echocardiographic examination showed functional improvement in CSC-Patch group. $(*, p<0.05$ compared to sham or Patch only group)

Furthermore, both EF and FS were improved in the CSC-Patch group (EF: $51.5 \pm 2.8 \%$; FS: $23.4 \pm 1.4 \%$ ) relative to the patch-only group (EF: $37.4 \pm 2.8 \%$; FS: $16.0 \pm 0.8 \%$ ), but no significant differences in these parameters was observed between the sham operation and patch-only groups (Figure $8 \mathrm{~B}$ ). These data indicated that the CSCPatch represents an effective means for preventing cardiac remodeling and facilitating myocardial regeneration.

\section{Discussion}

This study demonstrated that epicardial implantation of CSCs via PLLA patch achieved improvement in host integration of the cells thereby enhanced structural and functional heart regeneration in a rat MI model. A variety of studies documented the regenerative capacity of the epicardium in the adult mammalian heart $[32,33]$, which suggests epicardium as an optimal location to introduce factors improving the myocardial regenerative process [34]. It appears that quiescent epicardium in adult heart can be reactivated by cardiac damage including MI or ischemia/reperfusion stress then epicardium function as a reservoir of mesenchymal progenitor cells which respond to injury by migrating into the injured area to rebuilt damaged heart tissue. In this account, it is likely that exogenous epicardial CSC delivery mimic and stimulate endogenous regenerative process as shown in this study.

However, only few previous articles have investigated scaffoldmediated implantation of cardiac progenitor and stem cells on epicardium. Kim, et al. observed engraftment of nanofabricated scaffolds with autologous cardiosphere-derived cells (CDCs) and reported enhancement of retention and growth of transplanted cells, and their integration with the host tissue in a rat infarction model [9]. Gaetani, et al. reported epicardial application of 3-D construct of cardiac progenitor cells and gelatin/hyaluronic acid preserves cardiac function after myocardial infarction [35]. Similarly, Wang, et al. investigated BMSCs-loaded poly( $\varepsilon$-caprolactone) (PCL)/gelatin 
Kyung H (2018) Resident cardiac stem cells on fibrous poly (L-lactide) patch augment cardiac repair via in-patch differentiation and simultaneous migration into infarcted heart tissue

patch [36] and Piao, et al. designed BMMNC-seeded biodegradable poly-glycolide-co-caprolactone (PGCL) scaffolds [37] for epicardial activation and repair of the infarcted myocardium in spite of difference in cell type.

Scaffolds for stem cell therapy are intended to provide the cells with a suitable environment for long-term viability and efficient engraftment onto damaged tissues. Porosity of the scaffolds influence cellular and vascular infiltration [38]. Several studies have described the relationship between pore size and cellular infiltration, with small pores $(<85 \mu \mathrm{m})$ associated with poor cell attachment and migration [39]. Researchers have reported general limitations of the scaffolds, including small pore size and lack of structural adjustability, resulting in inadequate infiltration of cells and poor neovascularization. Conventional electrospinning methods generally yield relatively small pore sizes $(25-100 \mu \mathrm{m})$, resulting in reduced cellular infiltration. In an attempt to promote cellular infiltration into electrospun scaffolds, several techniques have been developed, including salt leaching, cryoelectrospinning, and ultrasonification [40]. The 3-D patch-type scaffold in this study could be easily reconstructed to have the proper volume and thickness, depending on the size of the lesion, by simple mechanical elongation so that it had spatial volume, porosity, and the mechanical support for myocardial regeneration [30]. Topology of the scaffolds have been dealt with the issue for directing transplanted cell's fate toward tissue-specific differentiation. Forced alignment of the stem cells affects their differentiation into certain lineages, especially neural cells [41] and CMCs [42], due to the directionality of their alignments in endogenous tissue. Mechanical expansion of the 3-D patch could induce the directionality of fiber alignment, which require for cardiacspecific topological condition. The scaffold with short durability may be insufficient for meeting the therapeutic demand in the injured site, possibly reduce the integrity of the host tissue. Overstayed scaffold in the host tissue may lead to adverse immune response including foreign body encapsulation and scar formation [43]. Sustained degradation of the 3-D in our study will provide sufficient mechanical support and microenvironment for cell engraftment to damaged myocardium. Increased gaps between the fibers in the 3-D patch by gradual degradation will be suitable for cell infiltration and further angiogenesis to construct new myocardial tissue. The 3-D patch in this study shows faster degradation kinetics (30\% in 4 weeks) compared to a PLLA nanofibrous scaffold in a relevant study (less than $5 \%$ in 30 days) [44]. This is likely to be due to the greater sparsity of our 3-D patch, which is beneficial for cellular infiltration and angiogenesis. Biocompatibility and biodegradability of the 3-D patch were confirmed by examination of cell viability on the patch and degradation profile over time. Seeded CSCs were regularly distributed throughout the 3-D patch in the form of stratified CMC 2 week after seeding without necrosis, which resemble endogenous myocardium tissue. This result might be related to the 3-D architecture and directional topology of the 3-D patch. Several studies emphasized that the dose of transplanted cells is crucial to the therapeutic efficacy of stem cell therapy. Accordingly, a great deal of effort has been dedicated to investigating the dose-response relationship of stem cell delivery. A previous study reported that the minimal effective dose of CSCs via intracoronary injection in a rat MI model was 3-7.5 $\times 10^{6}$, without any structural or functional improvement above this threshold [45]. Thus, the estimated therapeutic cell dose in human (average weight, $70 \mathrm{~kg}$ ) would be in the range $0.3-1.5 \times 10^{8}$ cells. In clinical trials using MSCs, transplantation of more than $10^{8}$ cells resulted in significant improvement of cardiac repair [46]. In this study, the expanded 3-D patch exhibited a great cell-loading capability $\left(>2.5 \times 10^{5} \mathrm{CSCs}\right.$ per $\left.\mathrm{mm}^{2}\right)$, enabling practical delivery of the human therapeutic dose of cells in a $4 \mathrm{~cm}^{2}$ patch.

A previous literature reported that intravenously injected MSCs appeared shortly viable, which is approximately $3 \%$ in a day after administration in rat MI model [47]. Another comparative study has shown that intramyocardial delivery produced the greatest cell retention in the heart than intra-aortic and intravenous injection [48]. Epicardial delivery of CSCs via the 3-D patch in our study may outperform these conventional methods for stem cell administration to heart as it permits precise targeting and accurate implantation of a larger number of cells to infarcted region of heart compared with intramyocardial delivery routes. The bioluminescence result supported the idea that the 3-D patch represents a novel strategy for stem cell delivery to damaged myocardium. In addition, the patch supported CSCs for their survival and cardiac-specific maturation, serving as a reservoir in which to allow the cells to infiltrate and integrated to damaged heart tissue in a localized and prolonged manner. The CSCs were viable further differentiated into mature CMCs in the patch without any differentiation-inducing factors on the host myocardium after transplantation. CSC-seeded 3-D patch became thick myocardium-like construct on the host myocardium with inner neovascularization from the host. It might represent the vascular supply from the host to the patch, which enable functional engraftment of the transplanted CSCs. The transplanted $\mathrm{CM}-\mathrm{DiI}^{+} \mathrm{CSC}$ incorporated predominantly into the site of application rather than distributed to upper atrial part with successful migration in inner part of host heart tissue including myocardium and endocardium. Derval, et al. reported that 3-D engraftment of EPC and MSC has improved cardiac function probably via a paracrine effect of the progenitors [49]. Both progenitor cells induced positive modifications of the infarcted myocardial tissue although scar area was not reduced by any of the cell types as compared to control mice. In the study, MSC, but not EPC, were able to migrate to the infarct scar but to a limited extent ( $1 \%$ of the scar cellularity) and any transdifferentiation of the MSC into endothelial or smooth muscle cells or CMCs was not observed. Kim, et al. suggested the availability of scaffold in the damaged heart as a niche-based source of stem cells for a continued repair of the heart tissue using nanofabricated scaffolds with autologous cardiosphere-derived cells (CDCs), which is confirmed by implantation of a layer of GFP-labeled CDCs and their integration on the host cardiac tissue [9]. Comparing with these literatures, CSC delivery via the 3-D patch in this study could be an optimal module to induce cardiac tissue regeneration. CSCs delivered via the 3-D patch may survive and induce indirect paracrine effects in a prolonged manner at sites of administration, triggering endogenous regenerative mechanisms including angiogenesis, stem cell homing and activation of the CSCs in host tissue. Successful transplantation and host integration of the CSCs were also demonstrated by the existence of the cells at the site of implantation which are characterized by colocalization of CMDiI and lineage-specific markers of mature cells in heart. This might be associated with thicker neotissue formation in the CSC-Patch group relative to the Patch group. Synergistically, the paracrine effect of the CSCs in patch is likely to contribute to angiogenesis. Newly formed vasculature could support the survival and functional engraftment of the implanted cells by the patch to host myocardium.

Our results also suggested the possible role of the patch to prevent cardiac remodeling post-MI. Left ventricular thinning and dilatation is a common form of physiological change after MI, and ultimately contributes to cardiac dysfunction [50]. The patch might act similarly to $L V$ restraint devices, which block adverse geometrical changes in the 
Kyung H (2018) Resident cardiac stem cells on fibrous poly (L-lactide) patch augment cardiac repair via in-patch differentiation and simultaneous migration into infarcted heart tissue

heart by physical wrapping for prevent further deterioration of cardiac function in accordance with the relevant literatures [28]. A marked reduction in cardiac remodeling observed in the CSC-patch group indicated that CSCs synergistically prevented cardiac remodeling with the patch while inducing regeneration.

CSC-seeded 3-D patch in this study efficiently promoted both cardiac tissue regeneration and functional improvement comparing with other studies. In Gaetani's study, mice treated with human cardiac-derived progenitor cells-printed hyaluronic acid/gelatin patch shows no significant improvement of $\mathrm{EF}$ in contrast of a significant improvement in mice treated with empty matrix when compared to the control group (EF from control $(11.47 \pm 2.20 \%)$, non-cell scaffold group $(20.49 \pm 2.37 \%)$ and CMPC-seeded scaffold group (17.44 \pm $2.09 \%)$ ) [35]. In Kim's study, stroke volume increased progressively in the CDC graft group despite lack of the statistical significance between control group and CDC-free graft group. In a related study using rat MI model, the group treated with MSC-seeded 3-D collagen patch showed statistical insignificance in improvement of cardiac functional parameters compared to the control group in rat MI model yet of increase of ventricular wall thickness and decrease of the left ventricle dilatation [51]. BMMNC-seeded PGCL scaffold in other literature showed attenuation of LV dilation and LV dysfunction compared to the sham-operated group even if no significant difference with noncell-seeded PGCL scaffold group in echocardiographic examinations (FS from control $(15.6 \pm 4.3 \%)$, non-cell scaffold group (31.8 \pm $11.9 \%)$ and BMMNC-seeded scaffold group $(32.5 \pm 8.6 \%))$. However our present study showed that CSC-Patch could induce remarkable increase of cardiac functional parameters (EF: $51.5 \pm 2.8 \%$; FS: 23.4 $\pm 1.4 \%$ ) as against the patch-only group (EF: $37.4 \pm 2.8 \%$; FS: $16.0 \pm$ $0.8 \%$ ), which is comparable value to healthy rat's (EF : $57 \% \pm 5.4 \%$; FS :29 $\pm 8 \%)[52,53]$.

Taken together, our results serve as a proof of principle to demonstrate the beneficial effects of epicardial delivery of CSCs via a $3-D$ patch-type PLLA scaffold on cardiac regeneration ; 1) improved cell survival at the damaged site, due to the biomimetic 3-D microenvironment; 2) improved engraftment of the CSCs in damaged myocardium by directed and localized delivery of cells in a concentrated manner; 3) mechanical support of the infarcted tissue, which decreases cardiac remodeling; 4) direct cardiomyogenesis and the indirect paracrine effect of the engrafted CSCs, which induces angiogenesis and cardiac tissue regeneration, ultimately resulting in recovery of cardiac function.

\section{Conclusion}

A 3-D PLLA scaffold customized specifically for the heart allowed for highly efficient delivery of the CSCs in vivo. The 3-D patch-type scaffold provided a biomimetic microenvironment for long-term survival of cells and increased the engraftment rate of transplanted cells onto damaged myocardium. CSCs transplanted via 3-D patch could regenerate CMCs and new vessels in the area of transplantation, thereby inducing structural and functional improvement of the heart in rat MI model. In summary, our results indicated that epicardial delivery of CSC via such 3-D patch represents a promising strategy for cardiac tissue regeneration.

\section{Acknowledgement}

This research was supported by the Bio \& Medical Technology Development Program of the National Research Foundation (NRF) funded by the Ministry of Science \& ICT (2015M3A9B4066662) and NRF grant funded by the Korean government (MEST) (2016K1A3A1A20006058).

\section{Data availability}

All data generated or analyzed during this study are included in this published article.

\section{References}

1. Krugliakov P, Sokolova I, Polyntsev D (2008) Cell therapy for myocardial infarction. Tsitologiia 50: 521-527.

2. Steinhauser ML, Lee RT (2011) Regeneration of the heart. EMBO molecular medicine 3: 701-712.

3. Rosenstrauch D, Poglajen G, Zidar N, Gregoric ID (2005) Stem cell therapy for ischemic heart failure. Tex Heart Inst J 32: 339.

4. Segers VF, Lee RT (2008) Stem-cell therapy for cardiac disease. Nature 451: 937

5. Sun Q, Zhang Z, Sun Z (2014) The potential and challenges of using stem cells for cardiovascular repair and regeneration. Genes Dis 1: 113-119.

6. Terzic A, Behfar A (2016) Stem cell therapy for heart failure: ensuring regenerative proficiency. Trends Cardiovasc Med 26: 395-404. [Crossref]

7. Weir C, Morel-Kopp MC, Gill A, Tinworth K, Ladd L, et al. (2008) Mesenchymal stem cells: isolation, characterisation and in vivo fluorescent dye tracking. Heart Lung Circ 17: 395-403. [Crossref]

8. Tano N, Kaneko M, Ichihara Y, Ikebe C, Coppen SR, et al. (2016) Allogeneic mesenchyma stromal cells transplanted onto the heart surface achieve therapeutic myocardial repair despite immunologic responses in rats. J Am Heart Assoc 5: e002815. [Crossref]

9. Kim DH, Kshitiz, Smith RR, Kim P, Ahn EH, et al. (2012) Nanopatterned cardiac cell patches promote stem cell niche formation and myocardial regeneration. Integr Biol (Camb) 4: 1019-1033. [Crossref]

10. Hasan A, Waters R, Roula B, Dana R, Yara S, et al. (2016) Engineered Biomaterials to Enhance Stem Cell-Based Cardiac Tissue Engineering and Therapy. Macromol Biosci 16: 958-977. [Crossref]

11. Dixit P, Katare R (2015) Challenges in identifying the best source of stem cells for cardiac regeneration therapy. Stem Cell Res Ther 6: 26.

12. Beltrami AP, Barlucchi L, Torella D, Baker M, Limana F, et al. (2003) Adult cardiac stem cells are multipotent and support myocardial regeneration. Cell 114: 763-776.

13. Srivastava D, Ivey KN (2006) Potential of stem-cell-based therapies for heart disease Nature 441: 1097. [Crossref]

14. Yellamilli A, van Berlo JH (2016) The role of cardiac side population cells in cardiac regeneration. Front Cell Dev Biol 4: 102. [Crossref]

15. Hendijani F (2017) Explant culture: An advantageous method for isolation of mesenchymal stem cells from human tissues. Cell Prolif 50: 2. [Crossref]

16. Zhu B, Murthy SK (2013) Stem cell separation technologies. Curr Opin Chem Eng 2: 3-7. [Crossref]

17. Smith RR, Barile L, Cho HC, Leppo MK, Hare JM, et al. (2007) Regenerative potentia of cardiosphere-derived cells expanded from percutaneous endomyocardial biopsy specimens. Circulation 115: 896-908. [Crossref]

18. Messina E, De Angelis L, Frati G, Morrone S, Chimenti S, et al. (2004) Isolation and expansion of adult cardiac stem cells from human and murine heart. Circ Res 95: 911921. [Crossref]

19. Kim JT, Chung HJ, Seo JY, Yang YI, Choi MY, et al. (2015) A fibrin- supported myocardial organ culture for isolation of cardiac stem cells via the recapitulation of cardiac homeostasis. Biomaterials 48: 66-83. [Crossref]

20. Wollert KC1, Drexler H (2005) Clinical applications of stem cells for the heart. Circ Res 96: 151- 163. [Crossref]

21. Dai W, Kloner RA (2011) Bone Marrow-Derived Cell Transplantation Therapy for Myocardial Infarction: Lessons Learned and Future Questions. Am J Transplant 112: 297-2301. [Crossref]

22. Kurtz A (2008) Mesenchymal stem cell delivery routes and fate. Int J Stem Cells 1: 1.

23. Li L, Chen X, Wang WE, Zeng C (2015) How to improve the survival of transplanted mesenchymal stem cell in ischemic heart? Stem Cells Int 2016: 9682757. [Crossref] 
Kyung H (2018) Resident cardiac stem cells on fibrous poly (L-lactide) patch augment cardiac repair via in-patch differentiation and simultaneous migration into infarcted heart tissue

24. Ye KY, Black LD (2011) Strategies for tissue engineering cardiac constructs to affect functional repair following myocardial infarction. J Cardiovasc Transl Res 4: 575. [Crossref]

25. Hamdi H, Planat-Benard V, Bel A, Neamatalla H, Saccenti L, et al. (2014) Long-term functional benefits of epicardial patches as cell carriers. Cell transplant 23: 87-96. [Crossref]

26. Araña M, Peña E, Abizanda G, Cilla M, Ochoa I, et al. (2013) Preparation and characterization of collagen-based ADSC-carrier sheets for cardiovascular application. Acta biomater 9: 6075-6083. [Crossref]

27. Fujimoto KL, Tobita K, Merryman WD, Guan J, Momoi N, et al. (2007) An elastic, biodegradable cardiac patch induces contractile smooth muscle and improves cardiac remodeling and function in subacute myocardial infarction. $\mathrm{J} \mathrm{Am}$ Coll Cardiol 49: 2292-2300. [Crossref]

28. Ravichandran R, Venugopal JR, Sundarrajan S, Mukherjee S, Ramakrishna S (2012) Minimally invasive cell-seeded biomaterial systems for injectable/epicardial implantation in ischemic heart disease. Int J Nanomedicine 7: 5969. [Crossref]

29. Fujita J, Itabashi Y, Seki T, Tohyama S, Tamura Y (2012) Myocardial cell sheet therapy and cardiac function. Am J Physiol Heart Circ Physiol 303: H1169-H1182. [Crossref]

30. Shim IK, Jung MR, Kim KH, Seol YJ, Park YJ (2010) Novel three-dimensional scaffolds of poly (L-lactic acid) microfibers using electrospinning and mechanical expansion: Fabrication and bone regeneration. J Biomed Mater Res B Appl Biomater 95: 150-160. [Crossref]

31. Berry MF, Engler AJ, Woo YJ, Pirolli TJ, Bish LT, et al. (2006) Mesenchymal stem cell injection after myocardial infarction improves myocardial compliance. Am J Physiol Heart Circ Physiol 290: H2196-H2203.

32. Limana F, Zacheo A, Mocini D, Mangoni A, Borsellino G (2007) Identification of myocardial and vascular precursor cells in human and mouse epicardium. Circ Res 101: 1255-1265. [Crossref]

33. Smits AM, Dronkers E, Goumans MJ (2017) The epicardium as a source of multipotent adult cardiac progenitor cells: Their origin, role and fate. Pharmacol Res 127: 129-140. [Crossref]

34. Mewhort HE, Svystonyuk DA, Turnbull JD, Teng G, Belke DD, et al. (2017) Bioactive Extracellular Matrix Scaffold Promotes Adaptive Cardiac Remodeling and Repair. JACC: Basic to Transl Sci 2: 450-464. [Crossref]

35. Gaetani R, Feyen DA, Verhage V, Slaats R, Messina E, et al. (2015) Epicardia application of cardiac progenitor cells in a 3D-printed gelatin/hyaluronic acid patch preserves cardiac function after myocardial infarction. Biomaterials 61: 339-348. [Crossref]

36. Wang QL, Wang HJ, Li ZH, Wang YL, Wu XP, et al. (2017) Mesenchymal stem cell-loaded cardiac patch promotes epicardial activation and repair of the infarcted myocardium. J Cell Mol Med 21: 1751-1766. [Crossref]

37. Piao H, Kwon JS, Piao S, Sohn JH, Lee YS, et al. (2007) Effects of cardiac patches engineered with bone marrow-derived mononuclear cells and PGCL scaffolds in a rat myocardial infarction model. Biomaterials 28: 641-649. [Crossref]

38. Szentivanyi A, Chakradeo T, Zernetsch H, Glasmacher B (2011) Electrospun cellular microenvironments: understanding controlled release and scaffold structure. Adv Drug Deliv Rev 63: 209-220. [Crossref]
39. Li WJ, Laurencin CT, Caterson EJ, Tuan RS, Ko FK (2002) Electrospun nanofibrous structure: a novel scaffold for tissue engineering. J Biomed Mater Res 60: 613-621.

40. Zhong S, Zhang Y, Lim CT (2011) Fabrication of large pores in electrospun nanofibrous scaffolds for cellular infiltration: a review. Tissue Eng Part B Rev 18: 77-87. [Crossref]

41. Leclair AM, Ferguson SS, Lagugné-Labarthet F (2011) Surface patterning using plasma-deposited fluorocarbon thin films for single-cell positioning and neural circuit arrangement. Biomaterials 32: 1351-1360. [Crossref]

42. Pijnappels DA, Schalij MJ, Ramkisoensing AA, van Tuyn J, de Vries AA, et al (2008) Forced alignment of mesenchymal stem cells undergoing cardiomyogenic differentiation affects functional integration with cardiomyocyte cultures. Circ Res 103 : 167-176. [Crossref]

43. Brown BN, Badylak SF (2014) Extracellular matrix as an inductive scaffold for functional tissue reconstruction. Transl Res 163: 268-285. [Crossref]

44. Moffa M, Polini A, Sciancalepore AG, Persano L, Mele E, et al. (2013) Microvascular endothelial cell spreading and proliferation on nanofibrous scaffolds by polymer blends with enhanced wettability. Soft Matter 9: 5529-5539.

45. Tang XL, Rokosh G, Sanganalmath SK, Tokita Y, Keith MC, et al. (2015) Effects of intracoronary infusion of escalating doses of cardiac stem cells in rats with acute myocardial infarction. Circ Heart Fail 8: 757-765. [Crossref]

46. Martin-Rendon E, Brunskill SJ, Hyde CJ, Stanworth SJ, Mathur A, et al. (2008) Autologous bone marrow stem cells to treat acute myocardial infarction: a systematic review. Eur Heart J 29: 1807-1818. [Crossref]

47. Nagaya N, Fujii T, Iwase T, Ohgushi H, Itoh T, et al. (2004) Intravenous administration of mesenchymal stem cells improves cardiac function in rats with acute myocardia infarction through angiogenesis and myogenesis. Am J Physiol Heart Circ Physiol 287: H2670-H2676. [Crossref]

48. Li SH, Lai TY, Sun Z, Han M, Moriyama E, et al. (2009) Tracking cardiac engraftmen and distribution of implanted bone marrow cells: comparing intra-aortic, intravenous, and intramyocardial delivery. J Thorac Cardiovasc Surg 137: 1225-1233. [Crossref]

49. Derval N, Barandon L, Dufourcq P, Leroux L, Lamazière JM, et al. (2008) Epicardia deposition of endothelial progenitor and mesenchymal stem cells in a coated muscle patch after myocardial infarction in a murine model. Eur J Cardiothorac Surg 34: 248254. [Crossref]

50. Firth BG, Dunnmon PG (1990) Left ventricular dilatation and failure post-myocardial infarction: pathophysiology and possible pharmacologic interventions. Cardiovasc Drugs Ther 4: 1363-1374.

51. Maureira P, Marie PY, Yu F, Poussier S, Liu Y, et al. (2012) Repairing chronic myocardial infarction with autologous mesenchymal stem cells engineered tissue in rat promotes angiogenesis and limits ventricular remodeling. J Biomed Sci 19: 93. [Crossref]

52. Higuchi T, Nekolla SG, Jankaukas A, Weber AW, Huisman MC, et al. (2007) Characterization of normal and infarcted rat myocardium using a combination of smallanimal PET and clinical MRI. J Nucl Med 48: 288-294.

53. Kilvington JA, Coleman H, Hansen B, Dierks H, Zhang W (2007) Myocardial infarct size estimation by echocardiography in an acute rat model. FASEB J 21: A1261-A1261.

Copyright: (C2018 Kyung H. This is an open-access article distributed under the terms of the Creative Commons Attribution License, which permits unrestricted use, distribution, and reproduction in any medium, provided the original author and source are credited. 